\title{
Cervical spondylotic radiculopathy precipitated by decompression sickness
}

\author{
Y L Yu, C M Chang, T H Lam, K M Ho, K Y Mok
}

Cervical spondylotic radiculopathy (CSR) is a relatively common problem after middle age, ${ }^{1-3}$ and is characterised by pain, segmental sensory disturbance, and motor deficits in the upper limbs. In acute cases, neck pain and stiffness are often present, and exertion or neck injury is the usual preceding event. We report a case of CSR precipitated by decompression sickness (DCS), which we believe has not hitherto been documented.

\section{Case report}

A 52 year old chief inspector of a tunnelling project had been working in a compressed air environment for some 35 years. About 13 years previously he had bends (type I DCS) affecting one leg, which was treated with no sequelae. A medical examination for precompressed air workers one year before presentation was satisfactory, and showed no neurological abnormality. Eleven months later, he developed the first episode of mild neck pain which resolved with oral medication given by his family doctor. $\mathrm{He}$ could not recall a history of neck injury at any time. One month later, while under decompression using the Blackpool tables ${ }^{4}$ after two exposures for a total of 57 minutes to compressed air at maximum working pressure of $2.6 \mathrm{~kg} / \mathrm{cm}^{2}$, he developed a severe pain in the neck and the right shoulder with radiation to both arms, then muscle twitching in both arms and paralysis of all four limbs. $\mathrm{He}$ was treated by recompression to a pressure of $3.0 \mathrm{~kg} / \mathrm{cm}^{2}$ according to the British medical code of practice for type II DCS. ${ }^{4} \mathrm{He}$ began to recover after about 30 minutes and was asymptomatic on discharge after treatment for 22 hours. One week later, without further exposure to compressed air at work, he experienced pain in the right shoulder, then weakness in the right arm. As paracetamol provided no relief, he received recompression treatment up to $4.0 \mathrm{~kg} / \mathrm{cm}^{2}$ according to the British medical code of practice for type II

Department of Medicine, University of Hong Kong Y L Yu, C M Chang, K M Ho, K Y Mok

Department of Community Medicine, University of Hong Kong

T H Lam
DCS for 25 hours. The pain did not resolve, however, and the right arm became weak. He was subjected to another course of pressure treatment using hyperbaric oxygen for eight hours but with no improvement.

$\mathrm{He}$ was then transferred to hospital. Plain radiographs of the cervical spine showed a posterior osteophyte of moderate size at the C5/6 level. The diameter of the sagittal canal was adequate with a minimum value of $15 \mathrm{~mm}$. Cervical myelography (fig 1) showed anterior thecal compression at the $C 5 / 6$ intervertebral level with deformity of the right C6 root sheath. Computer assisted myelography of the cervical region at the $\mathrm{C} 5 / 6$ level (fig 2) showed truncation of the right $\mathrm{C} 6$ spinal root probably by disc material; the spinal cord itself was not compressed. Neck traction was given but there was no relief of the severe pain and weakness in the right arm. Surgery was advised but the patient declined.

After treatment by acupuncture, the pain resolved completely, but weakness and wasting of proximal muscles of the right arm remained. His legs functioned normally and there was no disturbance of the sphincters. Examination eight months after the

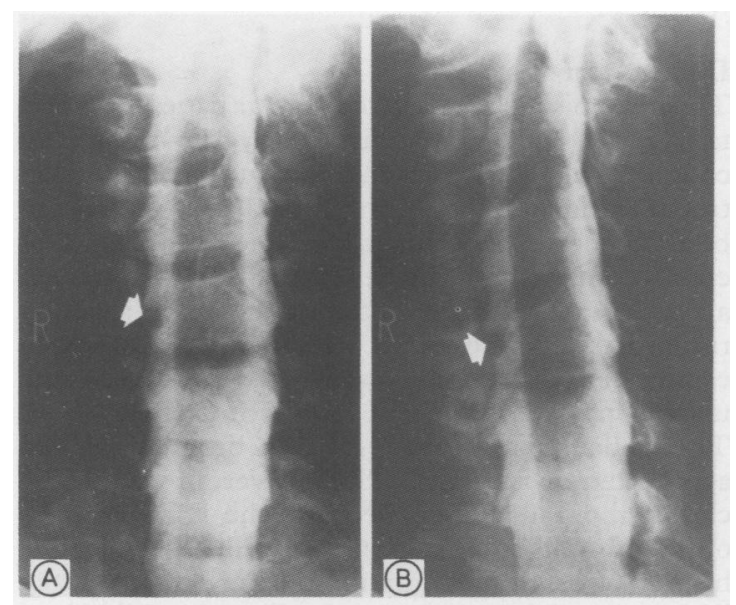

Figure 1 Cervical myelograms in $(A)$ posteroanterior and $(B)$ right oblique projections, demonstrating indentation of root sheath (arrow) at C5/6 level on the right. 


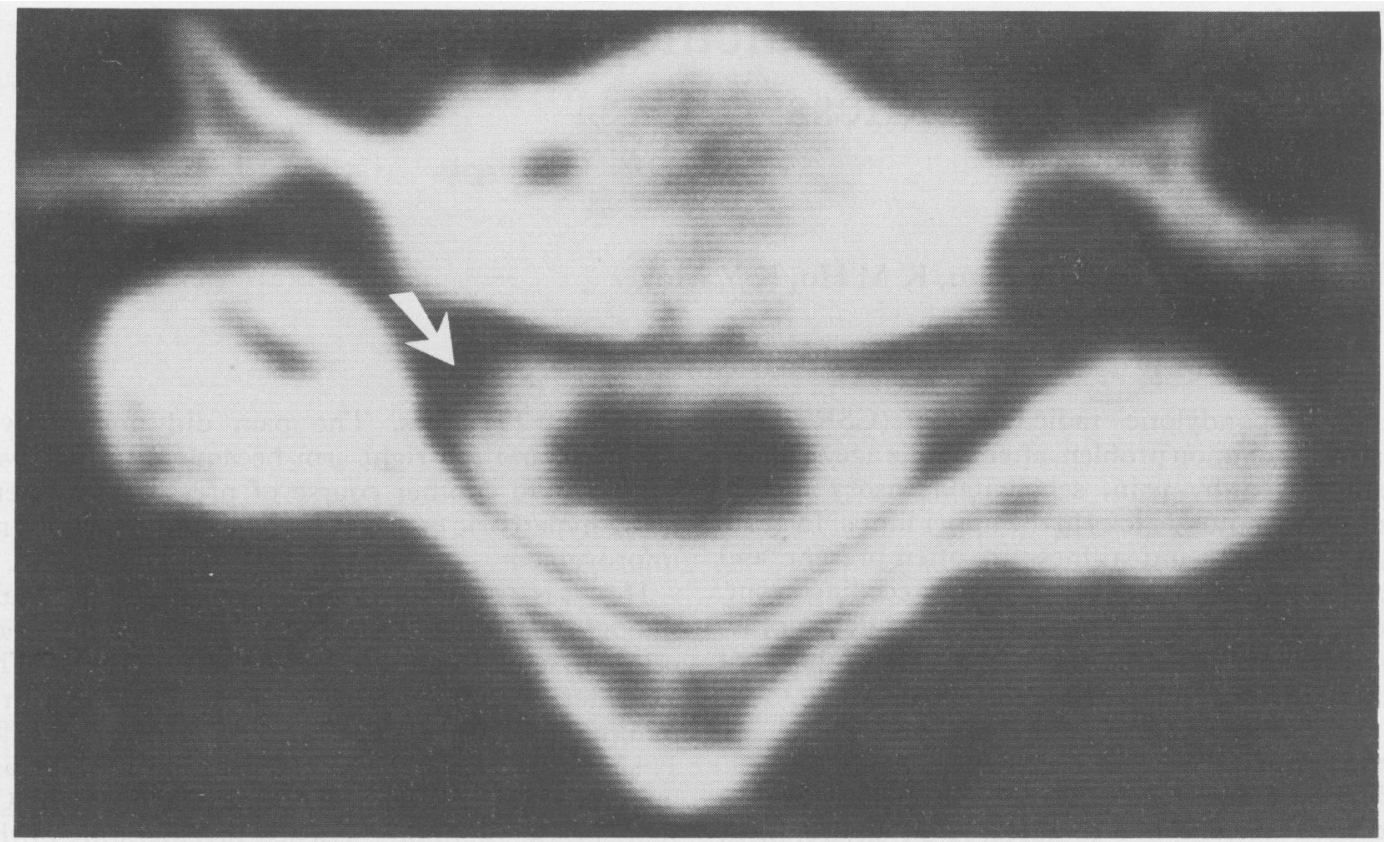

Figure 2 Computer assisted myelograms of the C5/6 level, showing truncation (arrow) of right C6 root by disc protrusion. The spinal cord was not compressed.

incident showed that neck movements were normal. In the right upper limb, the deltoid, infra and supraspinati and other upper arm muscles were wasted and weak (power, Medical Research Council grade 3/5). The lower limbs were normal. Apart from a diminished right triceps jerk, the tendon reflexes were unremarkable and the plantar responses were flexor. The pain, joint position, and vibration sensations were normal.

\section{Discussion}

The first episode of symptoms in our patient was due to type II DCS as confirmed by the rapid and complete relief of symptoms after one recompression treatment in air. The second episode was unlikely to be DCS because it occurred after one week of the first episode and without further exposure to compressed air at work. Also the symptoms were not relieved by recompression treatment. Radiological evidence established compression by spondylotic tissues as the underlying cause for the severe right $\mathrm{C} 6$ root lesion. The radiculopathy was probably brought on and aggravated by type II DCS, however, in view of the clear temporal relation between the DCS and the onset of root compression, as well as a negative history of usual precipitating factors such as heavy lifting or neck injury. A survey of major publications on CSR ${ }^{1-35-8}$ and on neurological manifestations of $\mathrm{DCS}^{9-14}$ produced no similar reports.
The pathogenesis of DCS in the spinal cord and brain is well established. ${ }^{15-19}$ The nervous tissues, especially myelin, are comparatively rich in lipid and hence absorb more nitrogen when the subject is in an environment of compressed air. During decompression, air bubble nucleation takes place, and if excessive, may cause direct compression of neural tissues, venous infarction, and abnormal clotting. Damaged tissues have an increased susceptibility to $\mathrm{DCS}^{17}$ and there is a predilection of pain only symptoms for previously injured joints. ${ }^{10}$ In our patient, the right C6 root compression by spondylosis had been present for some time but remained asymptomatic, as in many cases of subclinical spondylotic root compression. In the episode of DCS which preceded the root symptoms, bubbles may have been formed at the intramyelinic site of the nerve root and this, coupled with the compressive component, resulted in aggravation of the lesion and hence clinical manifestation.

Moreoever, during pre-employment medical examination, the patient was noted to be over age and should have been excluded from compressed air work. In view of the important nature of his work and his wide experience, however, he was permitted to work in compressed air with a restriction to a daily maximum exposure to four hours. Unfortunately, this precaution was not sufficient for the prevention of DCS as the episode of DCS occurred after only two exposures for a total of 57 minutes. Multiple 
exposures within a short period, lack of acclimatisation owing to infrequent and irregular exposure to compressed air, or both, could be contributing factors. The pressure of $2.6 \mathrm{~kg} / \mathrm{cm}^{2}$ was quite high. According to the British medical code of practice for work in compressed air, ${ }^{14}$ there should be no lowering of standards of medical examination of compressed air workers for key workers because many are older than average and so more liable to DCS, and they may be required to undergo several exposures in a day or even stay for the maximum permitted period of exposure. Hence, although it may be necessary to allow older key personnel to work in compressed air, both the doctors and the workers should be fully aware of the increased risk of DCS.

It should also be noted that cervical spondylosis is not specifically listed as a disqualifying condition for employment in compressed air in the United States ${ }^{20}$ or in Britain, ${ }^{4}$ although disease of the central nervous system is a disqualifying condition in Britain. Because cervical spondylosis and CSR are relatively common conditions after middle age and from the experience of the present case, the compressed air physician should take special precautions in the examination of these conditions. In cases of over age people with cervical spine pathology, it would be logical to disqualify the workers from work with compressed air to prevent complications of the spinal cord and roots owing to DCS.

Requests for reprints to: Dr Y L Yu, Department of Medicine, University of Hong Kong, Queen Mary Hospital, Hong Kong.

1 Frykholm R. Cervical nerve root compression resulting from disc degeneration and root sleeve fibrosis. A clinical investigation. Acta Chir Scand / Suppl] 1951;160:1-149.

2 Admas C. Cervical spondylotic radiculopathy and myelopathy. In: Vinken PJ, Bruyn GW, eds. Handbook of Clinical Neurology. Vol 26. Amsterdam: North Holland Publishing, 1977;97-112.
3 Yu YL, Woo E, Huang CY. Cervical spondylotic myelopathy and radiculopathy. Acta Neurol Scand 1987;75:367-73.

4 Medical Research Council Decompression Sickness Panel. Medical code of practice for work in compressed air. 3rd ed. London: Construction Industry Research and Information Association, 1982.

5 Hanflig SS. Pain in the shoulder girdle, arm and precordium due to cervical arthritis. $J A M A$ 1936;106:523-6.

6 Brain R, Northfield D, Wilkinson M. Neurological manifestations of cervical spondylosis. Brain 1952;75:187-225.

7 Wilkinson $M$. The morbid anatomy of cervical spondylosis and myelopathy. Brain 1960;83:589-616.

8 Brooker AEW, Barter RW. Cervical spondylosis. A clinical study with comparative radiology. Brain 1965;88:925-36.

9 Erde A, Edmonds C. Decompression sickness: a clinical series. $J$ Occup Med 1975;17:324-8.

10 Elliott DH, Kindwall EP. Manifestations of the decompression disorders. In: Bennett PB, Elliott DH, eds. The physiology and medicine of diving. 3rd ed. London: Baillière Tindall, 1982;461-72.

11 Dick APK, Massey EW. Neurologic presentation of decompression sickness and air embolism in sport divers. Neurology 1985;35:667-71.

12 Hoiberg A. Consequences of US Navy diving mishaps: decompression sickness. Undersea Biomed Res 1986;13:383-94.

13 Gorman DF, Edmonds CW, Parsons DW et al. Neurologic sequelae of decompression sickness: a clinical report. In: Bove $\mathrm{AA}$, Bachrach AJ, Greenbaum LJ, eds. Underwater and Hyperbaric Physiology IX. Bethesda: Undersea and Hyperbaric Medical Society, 1987;993-8.

14 Lam TH, Yau KP. Manifestations and treatment of 793 cases of decompression sickness in a compressed air tunneling project in Hong Kong. Undersea Biomed Res 1988;15:377-88.

15 Francis TJR, Pearson RR, Robertson AG, Hodgson M, Dutka AJ, Flynn ET. Central nervous system decompression sickness: latency of 1070 human cases. Undersea Biomed Res 1989;15:403-17.

16 Hallenbeck JM, Bore AA, Elliott DH. Mechanisms underlying spinal cord damage in decompression sickness. Neurology 1975;25:308-16.

17 Hallenbeck JM, Andersen JC. Pathogenesis of the decompression disorders. In: Bennett $\mathrm{PB}$, Elliott $\mathrm{DH}$, eds. The Physiology and Medicine of Diving. 3rd ed. London: Baillière Tindall, 1982;435-60.

18 Francis TJR, Pezeshkpour GH, Dutka AJ, Hallenbeck JM, Flynn ET. Is there a role for the autochthonous bubble in the pathogenesis of spinal cord decompression sickness? $J$ Neuropathol Exp Neurol 1988;47:475-87.

19 Francis TJR, Dutka AJ, Flynn ET. Experimental determination of latency, severity, and outcome in CNS decompression sickness. Undersea Biomed Res 1989;15:419-27.

$20 \mathrm{Kindwall}$ EP. Medical aspects of commercial diving and compressed air work. In: Zeng C, ed. Occupational Medicine: Principles and Practical Applications. Chicago: Year Book Medical Publishers, 1975;361-421.

Accepted 30 April 1990 